\title{
Study on the Level Measurement of Large Data Industry Based on Location Entropy
}

\author{
Xinpu Wang Mu Zhang \\ School of Finance, Guizhou University of Finance and Economics, Guiyang Guizhou \\ 550025, China
}

\begin{abstract}
During the development of information technology industry agglomeration and implementation under the background of the reality of economic and social development by leaps and bounds, analysis examines the nearly five years (excluding Hong Kong, Macao and Taiwan) all over the country more than the size of the electronic information industry manufacturing agglomeration level. The article using the theory of industrial agglomeration, respectively to calculate the country (excluding Hong Kong, Macao and Taiwan) electronic information industry above designated size manufacturing nearly five years of location entropy index, demonstrate the changes of the agglomeration level, and summarize the innovation and the shortcomings.
\end{abstract}

\section{Keywords}

Electronic information industry; industrial agglomeration; location entropy

\section{基于区位熵的大数据产业集聚水平测度 研究}

\author{
王新谱 张目 \\ 贵州财经大学金融学院, 贵阳, 贵州 550025, 中国
}

摘要: 在推动信息技术产业集聚发展和实现经济社会跨越式发展这一现实背景下，分析考察 了近五年全国各地（不含港澳台）规模以上电子信息产业制造业的集聚水平。本篇文章利用 产业集聚的理论，分别计算出了全国各地（不含港澳台）规模以上电子信息产业制造业近五 年的区位熵指数, 反映大数据产业集聚水平的变化情况, 最后总结本文的创新与不足之处。

关键词: 电子信息产业; 产业集聚; 区位熵

\section{1.引言}

大数据引领产业发展的新方向, 成为信息技术的热点。大数据产业是 指一切与大数据的产生与集聚、组织
与管理、分析与发现、应用与服务相 关的经济活动的集合，包含宽带网络 等基础设施服务, 数字内容服务、物 联网服务、位置服务等信息服务以及 智能交通、互联网金融和智慧城市等 
应用服务和智能终端与电子元器件等 电子产品制造。云计算、物联网和互 联网等新兴技术发展, 数据流量的爆 炸式增长和数据结构类型的高度复杂 化, 使得大数据技术受到广泛关注。 发达国家将大数据发展提升到战略位 置, 大数据成为全球新的技术制高点 和经济增长的新动力。在国家的高度 重视和大力支持下, 大数据在社会认 知、政策环境、市场规模和产业支撑 能力等多方面都取得较大进展, 开创 良好的发展局面。目前我国大数据在 政务、民生、金融、医疗等多个领域 得到广泛应用, 随着政策的完善、创 新的投入和产业环境的优化, 我国大 数据产业迎来了发展的黄金期。

为贯彻实施 “十三五” 规划, 研 究大数据产业的集聚水平对于实施国 家大数据发展战略, 推动大数据产业 快速发展具有重要作用。通过阅读大 量文献, 发现对大数据产业集聚水平 的研究较少, 采用区位摘来衡量地区 大数据产业集聚水平的文章更是少之 又少, 不足以支持对大数据产业发展 的深入研究。而产业的集聚程度能带 动地区经济, 有利于产生庞大的规模 效应和上下游产业, 形成完整的产业链 条, 降低成本, 共同利用信息和基础设 施, 提高资源利用率, 促进产业转移, 形 成扩散效应, 加快建成产业园区。电 子信息制造业是大数据产业的基础性 行业, 在反映地区大数据产业的集聚 水平上具有代表性。本文从电子信息 产业出发, 通过区位摘指数说明地区 的大数据产业集聚水平变化情况，反 映出该地区大数据产业的发展状况。

\section{2. 国内外研究综述}

产业集聚效应是一种常见的经济 现象, 是指产业经济活动在空间上集 中而产生的经济效果和吸引经济活动 向一地区靠近的向心力, 产业集聚可
以产生规模经济, 给企业带来经济效 益, 带动经济发展, 提高国民收入。

谭传龙 (2015) 选取指数实证测 量物流产业集聚水平，分析物流产业 的集聚现状和结构特征, 认为山东半 岛的物流产业集聚水平高于全国平均 水平。

孙慧（2009）提出产业集聚对于 制定产业、促进地区经济进步具有重 要的指导意义。产业集聚效应与地区 发展的关系研究, 依赖于对产业集聚 水平的测度研究。研究产业集聚水平 对促进产业发展作用重大。

关爱萍（2014）指出衡量产业集 聚水平的测度方法有行业集中度、空 间基尼系数、 E-G 指数等, 国内大量 产业测算集聚水平时使用区位商，测 算更加简单直观。

桑玉婷 (2017) 认为产业集聚是 高新技术产业发展的重要规律。只有 高新技术产业及其相关产业在高新区 扎根聚集, 并产生集聚效应, 高新区 才能形成持续性竞争优势, 大大增加 地区经济和国民收入，对其他地区产 生示范带头作用。因此, 研究集聚效 应有重要的意义。

Athreye（2001）通过对美国硅谷 和英国剑桥科技园的对比分析发现英 国剑桥科技园不如美国硅谷的原因, 发现英国剑桥科技园的成功搞技术企 业少，没能形成产业集聚效应。

这些研究皆表明产业集聚效应给 经济带来的促进作用是非常显著的。

\section{3.电子信息产业的发展现状}

我国电子信息产业多年保持平稳 较快增长。手机、微型计算机、网络 通讯设备、彩电等主要电子信息产品 的产量居全球第一, 技术创新能力大 幅提升, 龙头企业实力显著增强。

2015 年规模以上电子信息产业企 业个数达 5.8 万家, 电子信息制造企业 
1.99 万家，软件和信息技术服务企业 3.8 万家。全年完成销售收入达 15.4 万 亿元，同比增长了 $10.1 \%$ 。电子信息制 造业实现主营业务收入 11.1 万亿元， 同比增长 $8.1 \%$; 软件和信息技术服务 业实现软件业务收入 4.3 万亿元, 同比 增长了 $15.7 \%$ 。规模以上电子信息制造 业增加值同比增长 $10.5 \%$, 高于同期工 业平均水平 (6.1\%) 4.4 个百分点, 在 全国 41 个工业行业中增速居第 5 位; 收入和利润总额分别增长 $8.1 \%$ 和 $10.9 \%$, 分别高于同期工业水平 7.3 和 13.2 个百分点, 占工业总体比重分别 达到 $10.1 \%$ 和 $8.8 \%$, 比 2014 年提高 0.7 和 1 个百分点。 2015 年规模以上电 子信息产业制造业五大类行业中，电 子元器件的主营业务收入占全行业的 比重最高, 为 $30.3 \%$; 其他产业为其 他、通信、计算机和家电, 占比分别 为 $22.3 \% 、 21.4 \% 、 19.2 \%$ 、和 $6.8 \%$ 。

2015 年电子信息制造业主营业务收入 前五名省市为广东省、江苏省、山东 省、上海市和浙江省, 主营业务收入 分别为 31541 亿元、 25835 亿元、7343 亿元、6195 亿元和 4530 亿元。

全球信息技术创新进入新一轮加 速期, 云计算、大数据等新一代信息 技术快速演进，硬件、软件、服务等 核心技术体系加速重构, 引发电子信 息产业新一轮变革。智能化成为全球 电子信息产业的发展趋势, 近年来, 全球信息技术围绕人工智能掀起了新 一轮高潮, 以智能为核心的技术产品 创新在多个领域取得突破性进展。

\section{4. 电子信息产业集聚水平的测度方法}

\section{1 区位熵理论}

区位熵又称专门化率。熵, 是比 率的比率, 由哈盖特 (P. Haggett) 首先提出并运用到区位分析中。区位 熵能够衡量某一区域要素的空间分布
情况并反映出某一产业部门的专业化 程度以及某一区域在高层次区域的地 位和作用, 是衡量地区一个产业集聚 水平的有效指标。一般来说, 一个地 区的区位熵值越大, 则代表该地区该 产业集聚度越高, 越具有规模优势。 反之则相反。区位熵的计算方法为:

$$
L Q_{i}=\frac{D_{\mathrm{i}}}{G_{i}} \quad D_{i}=\frac{\mathrm{r}_{\mathrm{i}}}{r} \quad G_{i}=\frac{R_{\mathrm{i}}}{\mathrm{R}}
$$

公式中, $L Q_{i}$ 就是某地区的高新 技术产业中 $\mathrm{i}$ 产业的区位熵, $D_{\mathrm{i}}$ 为地 区的高新技术产业中 $\mathrm{i}$ 产业的主营业务 收入占该地区高新技术产业主营业务 收入的份额, $G_{\mathrm{i}}$ 为全国高新技术产业 中 $\mathrm{i}$ 产业的主营业务收入占全国高新技 术产业主营业务收入的份额。此处某 地区主营业务收入用 $r$ 表示, 全国的主 营业务收入用 $\mathrm{R}$ 来表示。

$L Q_{i}$ 越大，地区产业集聚水平越 高, $\mathrm{i}$ 是指规模以上电子信息产业制造 业。当区位熵大于 1 时, $\mathrm{D}$ 地的规模 以上电子信息产业制造业的集聚程度 在全国具有优势; 当区位熵小于 1 时， D 地的规模以上电子信息产业制 造业的集聚程度在全国处于劣势。区 位熵的计算方法简便易行，较明显反 映一个地区产业在全国范围内的优劣 势状况,一定程度上反映出一地区在 某产业层面的产业集聚水平。

\section{2 产业区位熵的计算}

现计算全国 31 个地区（不含港澳 台）规模以上电子信息产业制造业的 区位熵。规模以上是在我国境内注册 (不包括港澳台地区)年主营业务收入在 2000 万元以上的电子信息制造企业, 年主营业务收入 100 万元及以上的软 件和信息技术服务企业。电子信息产 业包含制造业和服务业, 服务业是指 软件行业, 制造业有雷达工业行业、 通信设备工业行业、广播电视设备工 业行业、电子计算机工业行业、家电 
制造工业行业、电子测量仪器工业行 业、电子工业专用设备工业行业、电 子元件工业行业、电子器件工业行 业、电子信息机电产品工业行业以及 电子信息专用材料工业行业。 $L Q_{i}$ 是 一地区的高新技术产业中 $\mathrm{i}$ 产业在全国 的区位熵。

表 1：2011-2015 年规模以上电子信息产业制造业 31 省（市、区）区位熵

\begin{tabular}{|c|c|c|c|c|c|}
\hline 年份 & & & & & \\
地方 & 2011 & 2012 & 2013 & 2014 & 2015 \\
\hline 北京 & 0.87 & 0.90 & 0.91 & 0.90 & 0.89 \\
\hline 天津 & 0.94 & 0.94 & 1.08 & 0.89 & 0.84 \\
\hline 河北 & 0.53 & 0.56 & 0.68 & 0.71 & 0.70 \\
\hline 山西 & 0.75 & 0.89 & 0.92 & 0.97 & 0.97 \\
\hline 内蒙古 & 0.42 & 0.72 & 0.52 & 0.60 & 0.44 \\
\hline 辽宁 & 0.76 & 0.70 & 0.69 & 0.66 & 0.64 \\
\hline 吉林 & 0.13 & 0.11 & 0.12 & 0.10 & 0.09 \\
\hline 黑龙江 & 0.07 & 0.10 & 0.11 & 0.13 & 0.14 \\
\hline 上海 & 1.06 & 1.10 & 1.10 & 1.09 & 1.08 \\
\hline 江苏 & 1.07 & 1.21 & 1.13 & 1.15 & 1.14 \\
\hline 浙江 & 1.04 & 1.02 & 1.03 & 1.07 & 1.08 \\
\hline 安徽 & 1.19 & 0.84 & 0.97 & 1.00 & 1.04 \\
\hline 福建 & 1.13 & 1.12 & 1.14 & 1.12 & 1.14 \\
\hline 江西 & 0.97 & 1.10 & 1.08 & 1.15 & 1.03 \\
\hline 山东 & 1.04 & 0.78 & 0.82 & 0.80 & 0.80 \\
\hline 河南 & 0.65 & 0.75 & 0.79 & 0.78 & 0.80 \\
\hline 湖北 & 0.91 & 0.73 & 0.82 & 0.79 & 0.74 \\
\hline 湖南 & 0.63 & 0.81 & 0.84 & 0.84 & 0.86 \\
\hline 广东 & 1.14 & 1.12 & 1.16 & 1.17 & 1.19 \\
\hline 广西 & 0.70 & 0.91 & 0.94 & 1.05 & 1.11 \\
\hline 海南 & 0.13 & 0.51 & 0.83 & 0.41 & 0.33 \\
\hline 重庆 & 0.97 & 0.99 & 1.09 & 1.06 & 1.03 \\
\hline 四川 & 0.83 & 0.83 & 0.83 & 0.86 & 0.85 \\
\hline 贵州 & 0.28 & 0.21 & 0.28 & 0.17 & 0.39 \\
\hline 云南 & 0.14 & 0.15 & 0.18 & 0.15 & 0.17 \\
\hline 西藏 & 0.00 & 0.00 & 0.00 & 0.05 & 0.04 \\
\hline 陕西 & 0.46 & 0.46 & 0.48 & 0.43 & 0.52 \\
\hline 甘肃 & 0.37 & 0.40 & 0.48 & 0.43 & 0.46 \\
\hline 青海 & 1.05 & 0.56 & 0.62 & 0.91 & 0.93 \\
\hline 宁夏 & 0.87 & 0.95 & 0.74 & 1.40 & 0.98 \\
\hline 新疆 & 0.71 & 1.76 & 0.03 & 4.49 & 2.28 \\
\hline
\end{tabular}

\section{4 规模以上的电子信息产业制造业的 分布状况}

由表中数据可知, 大数据产业规 模以上电子信息产业制造业五年来的 集聚水平在上海（2011 年-2015 年区位 熵分别为 $1.06 、 1.10 、 1.10 、 1.09$ 、 1.08 ）、江苏（2011 年-2015 年区位熵 分别为 $1.07 、 1.21 、 1.13 、 1.15$ 、 1.14 ）、浙江（2011 年-2015 年区位熵 分别为 $1.04 、 1.02 、 1.03 、 1.07$ 、 1.08 ）、福建（2011 年-2015 年区位熵 分别为 $1.13 、 1.12 、 1.14 、 1.12$ 、 1.14 ）、广东（2011 年-2015 年区位摘 分别为 $1.14 、 1.12 、 1.16 、 1.17$ 、 1.19）这五个省（市）一直较为稳定且 高于全国其他地区, 其中广东省的区 位熵在全国具有显著优势; 五年来规 模以上电子信息产业制造业的集聚水 平在河北（2011 年-2015 年区位熵分别 为 $0.53 、 0.56 、 0.68 、 0.71 、 0.70)$ 、 山西（2011 年-2015 年区位熵分别为 $0.75 、 0.89 、 0.92 、 0.97 、 0.97) 、$ 黑龙 江（2011 年-2015 年区位熵分别为 $0.07 、 0.10 、 0.11 、 0.13 、 0.14)$ 、湖南 （2011 年-2015 年区位熵分别为 0.63 、 $0.81 、 0.84 、 0.84 、 0.86$ ）、广西 ( 2011 年 -2015 年区位摘分别为 $0.70 、 0.91 、 0.94 、 1.05 、 1.11$ ）五省 不断提高, 其中广西省的产业集聚增 长最快; 只有辽宁省规模以上的电子 信息产业制造业五年来的产业集聚水 平（2011 年-2015 年区位熵分别为 $0.76 、 0.70 、 0.69 、 0.66 、 0.64)$ 是不断 下降的; 规模以上电子信息产业制造 业五年来的集聚水平在北京（2011 年2015 年区位熵分别为 $0.87 、 0.90$ 、 $0.91 、 0.90 、 0.89)$ 、天津（2011 年2015 年区位熵分别为 $0.94 、 0.94$ 、 $1.08 、 0.89 、 0.84$ ) 、海南（2011 年2015 年区位熵分别为 $0.13 、 0.51$ 、 $0.83 、 0.41 、 0.33$ ）、重庆（2011 年2015 年区位熵分别为 $0.97 、 0.99$ 、 $1.09 、 1.06 、 1.03$ ）、四川（2011 年2015 年区位熵分别为 $0.83 、 0.83$ 、 $0.83 、 0.86 、 0.85$ ）的变化趋势是先上 
升后下降。反映产业集聚水平变化情 况的折线图如下:

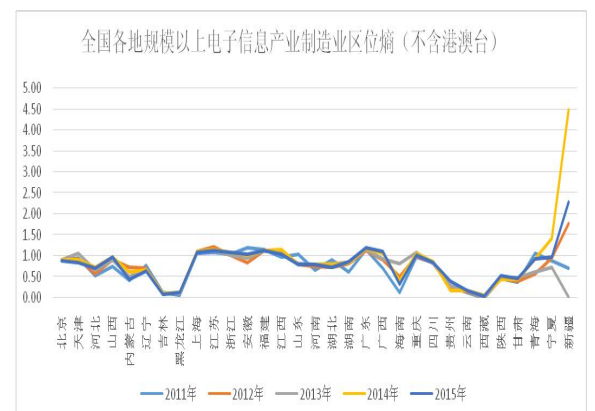

图 1: 2011-2015 年规模以上电子信息产业制造 业 31 地区区位熵变化.

\section{3 区位摘变动因素分析}

2011 年是 “十二五” 规划的开局 之年, 在复杂多变的外部环境和调结 构、转方式的大背景下, 当年北京 市、天津市、海南省、重庆市和四川 省五省、市的电子信息产业取得了可 喜的成果。五省、市抓住国家大力发 展战略性新兴产业的机遇, 支持本省 电子信息产业的发展, 经济效益不断 增强。2015 年, 宏观经济处于下行, 电子信息产业的集聚水平略有降低。 尤其是北京市的传统产业面临深度调 整, 新产业快速发展, 附加值低的组 装、加工代工类产品在本地区行业中 的比重快速下降, 影响了集聚水平。

2011 年-2015 年上海市、江苏省、 浙江省、福建省和广东省五省市尽管 受宏观经济下行影响, 但保持稳定的 原因是优越的地理位置。五省市均位 于沿海地区, 一方面制造业自始至今 都比内陆省份较为发达, 另一方面, 五省市是中国的大门, 较多的接触国 外的先进技术，拥有高素质的人才， 并不断优化产业布局, 尤其是广东省 和福建省是最早设立经济特区的省 份, 这是发展电子信息产业等高科技 产业的先天优势。上海市和浙江省政 府面对经济下行, 迎难而上, 主动作
为, 行业整体运行平稳, 转型升级成 效明显, 创新能力明显提升, 产业体 系不断完善。总体上, 五省市都具有 良好的产业基础, 呈现稳步增长的态 势, 具有领先的竞争优势。

2011 年-2015 年河北省、山西省、 黑龙江省、湖南省和广西省在不利的 经济下, 集聚水平不断提高的原因在 于各省独特的发展战略。首先, 河北 省抓住国家大力发展战略性新兴产业 的机遇, 为电子信息产业的发展提供 内在动力, 围绕 “十二五” 发展规 划, 积极培育新增长点。利用廊坊国 际经济贸易洽谈会、厦门 “9.8 经贸洽 谈会”、河北省信息产业周等平台召 开产业招商活动, 组织河北半导体照 明产业代表团赴台交流洽谈，达成多 项合作意向，获得国家、省技改资 金、电子发展基金。然后，山西省在 “转型跨越发展, 再造一个新山西” 的带领下, 实施国家资源型经济转型 综合配套改革试验政策，落实有关会 议和文件精神, 集中在八大优势行 业, 先行先试的方针为山西省承接境 外暨沿海电子信息产业梯度转移创造 有利条件, 传统产业升级都把电子信 息作为重点发展对象。其次, 黑龙江 省电子信息制造业坚持科学发展观, 深入调研与合理谋划, 进行专题讨论 和走访 10 次, 深入本省 28 家企业, 了解状况, 解决问题。面对欧债危机 的影响, 推进产品结构调整, 加快产 业升级。湖南省电子信息产业围绕构 建多点支撑产业发展的新格局战略, 突出大企业培育, 大项目建设和产业 链拓展, 产业发展取得长足进步。面 对严峻的形势, 坚定不移调结构, 牢 牢把握 “稳中求进” 的工作基调, 以 转型升级为主线, 保持平稳增长。广 西省发展电子信息产业是广西 “十二 五” 期间计划重点发展的 14 个亿元产 业之一，连续几年保持平稳快速的发 展态势, 电子信息产业年年创新高。 
辽宁省的区位熵近五年不断下降 是因为本省近几年投资少, 大项目也 不多, 缺少龙头企业的带动作用。同 时本省的产业规模小、布局分散, 电 子信息制造业产业链短, 配套设施不 完善, 产品对外依存度大, 竞争处于 弱势。省内企业出现问题, 大显集团 解体、路明集团出现经营困难, 华录 集团出口减少、日资企业部分产能转 移，使得辽宁省的电子信息制造业整 体呈现负增长。

\section{5.本文的创新与不足之处}

本文立足于大数据产业的基础性 产业一电子信息产业，用区位熵测度 各地规模以上电子信息产业制造业的 集聚水平。本文的创新点之一在于测 度大数据产业集聚水平这一新行业、 新领域, 在此之前, 只有很少的文献 和期刊衡量过这一产业的集聚水平; 创新点之二在于采用区位熵的测度方 法, 计算过程更加简单, 结果直观明 了, 本文为研究大数据产业集聚水平 提供了方法借鉴和理论指导。

本文的不足之处首先是涵盖整个 大数据产业的数据不能完全获取, 因 此仅衡量电子信息产业不能非常全面 的反映整个大数据产业的集聚水平; 其次, 测度集聚水平的衡量指标是主 营业务收入, 由于数据方面的原因, 指标不够精确。这些方面都是需要在 以后的研究中继续完善的地方。

\section{致谢}

基金项目：本文获得 2017 年度第 二批贵州省基础研究计划（软科学类 别）项目（黔科合基础〔2017〕15161）: 贵州大数据产业、生态文明建设 与金融集聚耦合协调发展研究; 2017 年度贵州财经大学校级科研项目（青
年项目）“贵州大数据产业集聚效应 及金融支持体系研究” 资助。

\section{参考文献}

[1] 谭传龙. 山东半岛物流产业集聚水 平测度与结构特征分析 [D].中国海 洋大学, 2015 .

[2] 孙慧,周好杰. 产业集聚水平测度方 法综述 [J]. 科技管 理 研 究,2009,29(06):449-451.

[3] 关爱萍,陈锐. 产业集聚水平测度方 法的研究综述 [J]. 工业技术经 济,2014,33(12):150-155.

[4] 桑玉停. 我国高新区的产业集聚效 应研究[D].深圳大学,2017.

[5] Athreye. Agglomeration and Growth: A study of the Cambridge Hi-Tech Cluster[R]. Stanford: Stanford Institute for Economic Policy Research, 2001:1-46.

[6]市经信委.电子通信产业科.我国大 数据产业发展即将迎来 “黄金期” [EB/OL]. http://www.yueyang.gov.cn/jxw/7317 /content 692535.html.

[7] 信息产业报道.我国电子信息产业现 状和发展趋势 [EB/OL]. http://m.sohu.com/a/133019546_4876 $12 / ?=1 \& \mathrm{v}=3$

[8] 李岩. 战略性新兴产业发展的金融 支持效应研究 [D]. 贵州财经大 学, 2015 .

[9] 周炣,陈梅,王蕾. 基于区位熵指数的 陕西省金融产业集聚水平研究 [J]. 统计与决策,2014,(24):176-179. 